\title{
Conceptualising uncertainty in environmental decision-making: the example of the EU Water Framework Directive
}

\author{
Katja Sigel $^{1}$, Bernd Klauer ${ }^{1}$ and Claudia Pahl-Wostl ${ }^{2}$ \\ ${ }^{1}$ Helmholtz Centre for Environmental Research - UFZ, Department of \\ Economics, Germany \\ ${ }^{2}$ Institute of Environmental Systems Research (USF), University of \\ Osnabrück, Germany
}

Keywords: uncertainty; certainty; lack of knowledge; pure ignorance; environment; decision-making; EU Water Framework Directive

\section{Table of contents}

1. Introduction 2

2. A conceptual framework for describing uncertainty in environmental decision-making

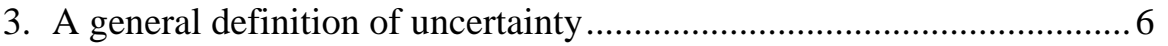

4. Complementary views on uncertainty ................................................. 9

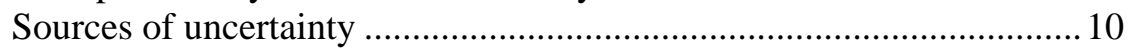

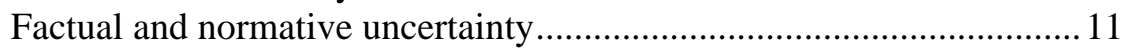

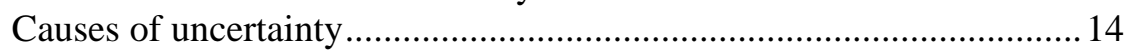

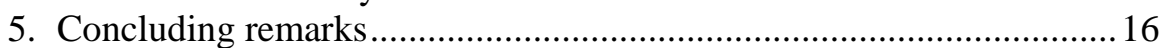

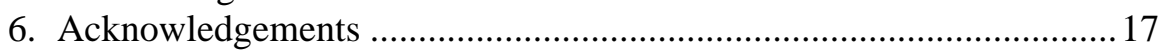

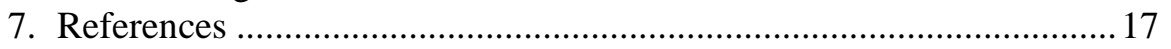




\section{Introduction}

In our daily life we often have to act and decide under uncertainty - this holds for our private life as well as for our public life. For example we have to take a decision even if we are in doubt as to what goal to pursue or what actions to take in order to achieve this goal. Often, the consequences of particular actions are ambiguous and can only be described vaguely. In general, uncertainty makes it difficult to take good and reasonable decisions.

In the context of environmental decision-making the problem of uncertainty recently receives a lot of attention - from the part of science as well as from the part of politics and administration. On quite different ways it is pointed out that uncertainty needs to be dealt with when developing solutions for environmental problems (e.g. Faber et al. 1992; Handmer et al. 2001; Harremoes 2003; Morgan and Henrion 1990; Pahl-Wostl 2002, 2007). This can be observed very well within the present discussion about climate change and possible consequences for water management where a long-term and global perspective is crucial (BMU 2007; Pahl-Wostl et al. 2006). Climate change and the need for adaptation should for example be taken into account in the planning of large-scale infrastructure such as reservoirs. Changes in precipitation patterns and their influence on water supply and agriculture may have repercussions of global dimensions. But also less severe environmental problems require some awareness about uncertainty if they shall be solved in a sustainable way.

Why is dealing with environmental problems strongly affected by uncertainty? One reason is that environmental problems often are regarded as complex because they comprise a lot of dynamic processes and interactions. Non-linear feedback processes lead to threshold effects and surprises. Complexity makes it difficult to describe such problems precisely and forecast the effect of potential solutions. Further, finding solutions for environmental problems requires a large amount of knowledge and information to provide a sound base for decision making but often not all of the required knowledge is available. Often the knowledge is unsystematic, fragmentary and therefore not clear (cf. Faber and Manstetten 2003, p. 23). It is also typical for environmental problems that the knowledge is spread over different scientific disciplines from natural sciences to social sciences and cannot be merged easily. Also the communication between scientists and practitioners often poses problems. All these issues contribute to the fact that in environmental decision-making uncertainty plays an important role. 
In this paper the problem of dealing with uncertainty in environmental decision-making is explored using the concrete example of the European Water Framework Directive (WFD). The WFD is a legislative framework designed to protect and improve the quality of all water resources in the European Union. It was published and entered into force in December 2000. The central environmental objective of the WFD is to achieve a socalled 'good status' of all European coastal and surface waters as well as of groundwater by 2015. The good status is defined by the WFD (Art. 4 and Annex V WFD) as a minor deviation of a natural, undisturbed water status. Parameters for assessing the status of water (depending of the type of waters) include the concentration of certain substances, physicochemical parameters like temperature and $\mathrm{pH}$-value, surface water morphology and structure as well as particularly biological parameters like the abundance of certain fish, macrophytes, and phytobenthos. Only in a few exemptions less stringent environmental objectives (Art. 4(5) WFD) or extensions of deadlines (Art. 4 (4) WFD) could be justified. For artificial and heavily modified water bodies like canals or drinking water dams the environmental objectives of a good status (particularly with respect to the ecological parameters) are also modified (Art. 4 (3) WFD).

On the basis of an assessment of the status quo of the water bodies in 2004 and of the results of water monitoring, the competent authorities are obliged to establish for each river basin district in Europe a management plan including a programme of measures until 2009 where it is described which measures will be taken by the EU Member States in order to reach the good status and the other environmental objectives of the WFD. The authorities' task is to select the appropriate measures necessary for improving the water status. Thereby they are asked to take into account the cost-effectiveness of the selected combinations of measures.

The implementation of the WFD implies a big challenge for the respective competent authorities. The selection of measures requires information about the current status of the waters, the causes of failing the good status, the potential measures for improving the status, the effects of these measures on the status, their costs as well as their side effects and their difficulties in implementing them (Klauer et al. in press). In many cases the authorities do not have a comprehensive knowledge basis for the decisions necessary to implement the WFD - hence, they have to act and decide under uncertainty.

Take, for instance, the description of the status of all water bodies that all member states must have carried out according to Annex II WFD until December 2004. This not only involves uncertainties in measurements of environmental variables but also uncertainties in assessing the sources of pressures (Annex II 1.4 WFD) as well as the uncertainties regarding the 
probability that water bodies will not reach good status. Or take the requirement to decide which particular water bodies with intensive human activities will be exempt from the overall goal to reach 'good' status and thus only need to reach less stringent environmental goals (Art. 4(5) WFD). Often, information concerning the properties of these water bodies and their deterioration by human activities is lacking; furthermore, of what level should the less stringent goals be? Or take, finally, the measures that will be decided upon to reach the goals of the directive. Mostly, their effectiveness can only be guessed - for reasons of scientific nature but also concerning the willingness of the addressees to comply with the rules. These are decisions under uncertainty in the implementation of the WFD.

Obviously, uncertainty can negatively affect the achievement of the WFD`s goals. Uncertainty in the implementation of the WFD is also relevant given that the decisions of the competent authorities are public decisions. In order for public decisions to be transparent and open to scrutiny and possible criticism, uncertainty needs to be clearly spelt out and reported during the decision-making process.

This contribution is based on the results of a study that takes the implementation of the WFD as an example for investigating the problem of environmental decision-making under uncertainty (Sigel in press). Based on the assumption that a deep understanding of uncertainty is a precondition for developing strategies for dealing with uncertainty, the specific objective of the study is to develop a conceptual framework to describe uncertainty in the implementation of the WFD in a systematic and differentiated way. Such a systematic approach is largely lacking in the analysis of the implementation of the WFD but also more generally in the analysis of the implementation of other environmental policies. The approach developed adopts the perspective of the major decision making authority. The development of the framework is based on a broad literature study and two empirical studies: (i) A text analysis of the WFD as well as three 'guidance documents', which are part of the common implementation strategy (CIS) for the WFD, namely 'Guidance for the analysis of pressures and impacts' (Impress 2003), 'Economics and the environment' (Wateco 2003) and 'Guidance on the planning process' (Proclan 2003). (ii) Expert interviews with representatives from German water management authorities that have the responsibility to implement the WFD. In both empirical studies the leading questions are (i) what do the experts understand by the term 'uncertainty' and (ii) how do they deal with uncertainty. The empirical studies were considered essential to establish a close relationship to reality and to illustrate the conceptual framework of uncertainty by means of examples from the WFD. 
The paper is organized as follows: In the next two sections, we describe the conceptual framework of uncertainty, consisting of a general definition of uncertainty and different views on uncertainty. The paper concludes with some considerations about the consequences of a thorough description of uncertainty and good decision making under uncertainty.

\section{A conceptual framework for describing uncertainty in environmental decision-making}

In the recent environmental literature uncertainty has been treated in quite different ways and numerous conceptualisations have been put forward (e.g. Brown et al. 2005; Faber et al. 1992; Funtowicz and Ravetz 1990; Klauer and Brown 2004; Smithson 1989; van Asselt 2000; Walker et al. 2003; Wynne 1992). Within a literature study we investigated to what extent these approaches are suitable to describe uncertainty in the implementation process of the WFD. For this purpose, the theory of probability, the classical economic decision-making theory and the taxonomies of uncertainty of Faber et al. (1992), Brown et al. (2005) and Walker et al. (2003) were further analysed. It could be shown that these approaches fail to provide a sufficiently deep insight into the phenomenon of uncertainty affecting the decisions within the WFD (Sigel in press). But several important aspects of uncertainty like 'subjectivity', 'causes' or 'reducibility' could be identified and incorporated in the conceptual framework of uncertainty.

The conceptual framework of uncertainty aims to describe uncertainty in a systematic and differentiated in the context of decision-making. In the case of the WFD the decisions are taken by the competent authorities who have the responsibility to implement the WFD. By means of the concept the competent authorities can gain a deeper understanding of uncertainty which may be helpful for the development of strategies for dealing with uncertainty.

The focus of the concept lies on uncertainty from the viewpoint of one decision-maker. Uncertainty resulting from the fact that for instance in the case of the WFD every competent authority consists of different persons interacting among each other and whose decisions are embedded in a multilayer political context is not investigated further. ${ }^{1}$ This does not imply that these uncertainties are considered to be irrelevant. However, they require different strategies to deal with them. Including them in the same

\footnotetext{
${ }^{1}$ In the literature this kind of uncertainty often is described as 'ambiguity', 'interaction uncertainty' or 'political uncertainty' (Handmer et al. 2001: XV; Morgan und Henrion 1990: 24; Walker und Marchau 2003).
} 
level of depth would go beyond the sope of the work presented here. We advocate a stepwise process to keep the complexity within manageable bounds and support the development of a systematic approach.

The concept consists of a general definition of uncertainty and five complementary views on uncertainty: (i) Typology of uncertainty on the basis of the theory of probability, (ii) sources of uncertainty, (iii) factual and normative uncertainty, (iv) causes of uncertainty and (v) reducibility of uncertainty (see table 1).

\section{Table 1: Structure of the concept of uncertainty}

- General definition of uncertainty

- Views on uncertainty:

- Typology of uncertainty on the basis of the theory of probability (i)

- Sources of uncertainty (ii)

- Factual and normative uncertainty (iii)

- Causes of uncertainty (iv)

- Reducibility of uncertainty (v)

The general definition serves as a broad characterization of uncertainty and provides the basis for an advanced description of uncertainty by use of different 'views on uncertainty'. Every 'view' highlights one specific aspect of uncertainty. As they are complementary they add up to a broad and differentiated description of uncertainty. This can be imagined by different spotlights illuminating one object from different points of view. Consequently, the relationship between the five 'views' is not as systematic as it is typical for classical taxonomies. However, complementary perspectives enrich the understanding of the multi-facetted nature of uncertainty. The 'views' are strengthened by further definitions.

In the following the different parts of the concept of uncertainty are described in detail. For the purpose of a better understanding the theoretical thoughts will be illustrated by concrete examples from the WFD being based on the empirical studies. These examples are separated from the text by shaded frames.

\section{A general definition of uncertainty}

In the following we will distinguish between the terms uncertainty, certainty, lack of knowledge and pure ignorance. 
Definition of uncertainty: A person is uncertain if he/she lacks confidence about his/her knowledge relating to a concrete question.

If a person wants to describe his uncertainty relating to a concrete question he has to reflect his knowledge. Hence, uncertainty as it is understood here is subjective and comprises two layers: Knowledge and confidence about knowledge. This implies that uncertainty always requires an attitude of openness and a person's ability to assess the reliability of his knowledge.

\section{The understanding of uncertainty in the WFD}

The WFD does not refer to 'uncertainty' as such. Instead, the converse expression 'adequate level of confidence and precision' is used. For example in relation to the frequency of monitoring it is said:

Frequencies shall be chosen so as to achieve an acceptable level of confidence and precision. Estimates of the confidence and precision attained by the monitoring system used shall be stated in the river basin management plan (Annex V 1.3.4 WFD).

Instead of the term 'adequate' (as applied to the level of confidence and precision), the WFD also uses the expressions 'sufficient' and 'acceptable'. The term 'confidence' expresses similar to the definition of uncertainty given here the subjectivity of uncertainty. Through the term 'precision' the WFD expresses additionally the objective nature of uncertainty.

The confidence about knowledge may range from being certain to admitting that he knows nothing of use. In other words: The spectrum of uncertainty ranges between two extreme states: Certainty and lack of knowledge (see figure 1).

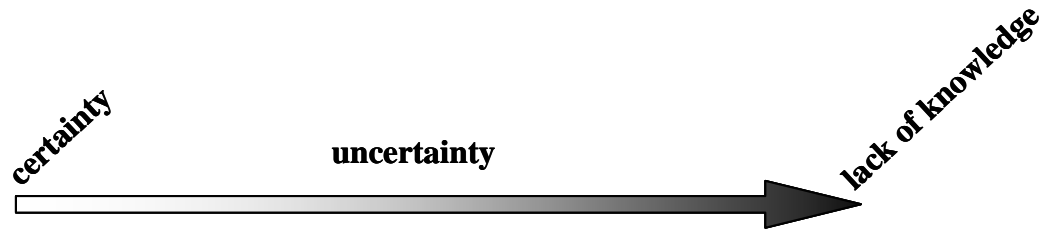

Fig. 1. The spectrum of uncertainty is ranging from 'certainty' to 'lack of knowledge'.

Practically, it is hardly possible to distinguish clearly between certainty, uncertainty and lack of knowledge because there is a continuous transition from certainty to lack of knowledge. In many cases certainty and lack of knowledge also can be interpreted as 'very low uncertainty' or 'very high 
uncertainty'. Nevertheless, for deepening the understanding of uncertainty it is helpful to define also these two extreme forms of uncertainty:

Definition of certainty: A person is certain if he/she is confident about his/her knowledge relating to a concrete question.

Definition of lack of knowledge: Lack of knowledge is a state where a person lacks knowledge relating to a concrete question. Nevertheless, the person is able to specify the reference point of his/her lacking knowledge.

\section{Examples for certainty in the implementation of the WFD}

An example for 'certainty' in the sense as we defined it here can be found in the WFD guidance document Impress in a short paragraph about modelling approaches for assessing the impacts for a water body:

Such models, if applied appropriately, are generally good at representing the water quality along a river in which the inflows from tributaries and point sources are well known or can be estimated reliably (Impress 2003: 35).

In the following example taken from the expert interviews a water manager expresses his certainty about punctual discharges:

What we know quite well are punctual discharges, in other words sewage plants (interview statement).

In case of lack of knowledge a person doesn't have any knowledge he could evaluate regarding its reliability. However, the person has (already) an idea what he could or should know relating to a concrete question. This means, that the person is able to describe the reference point of his lacking knowledge or rather is already aware of a concrete problem or question.

\section{Examples for lack of knowledge in the implementation of the WFD}

The expression 'gaps in information and knowledge' used by the guidance document Wateco comes very close to the expression 'lack of knowledge' as it is defined here. In the context of the economic analysis Wateco points out that the 'information and knowledge base' has to be improved by 'filling key information and knowledge gaps' (Wateco 2003: 32). Similar expressions used by Wateco are 'gaps in technical expertise', 'gaps in available data', 'information and knowledge needs' or 'research needs'. According to Wateco these gaps have to be filled over 
time. Hence, Wateco refers here to a form of reducible uncertainty.

In the following example a water manager expresses his lack of knowledge about the effectiveness of fish pathways:

That starts with the fish pathway, that one can't foresee if it will be accepted by the fishes or not. There are experiments where the fishes eventually come up but not come down because they can't find it: There are so many possibilities, that nearly is impossible to make predictions (interview statement).

Uncertainty (including certainty and lack of knowledge) is a state characterised by the reflection and confidence of a person in relation to his knowledge. The person is able to reflect his knowledge or rather to specify the reference point of his lacking knowledge. Consequently, uncertainty is situated within the knowledge horizon of a person.

Now we want to address a domain being out of the range of uncertainty and the concept of uncertainty developed here: Pure ignorance. Pure ignorance cannot be described or defined but only be known in an abstract sense. According to Faber et al. (1992: 233) pure ignorance is of an indefinite nature, like the future itself. It cannot be limited or constrained to any particular area of knowledge, as it encompasses all areas of life and development. We can identify pure ignorance only ex post for example when things happen that makes us aware of a problem we did not pay any attention before. Dealing consciously with pure ignorance is only possible insofar as we can be keen to broaden our horizon of knowledge continuously. This corresponds with the adoption of an attitude of openness and awareness as to unexpected events. With respect to the development of strategies for dealing with uncertainty it is important to be aware that pure ignorance exists and that there is a continuous transition from uncertainty to pure ignorance.

\section{Complementary views on uncertainty}

The concept of uncertainty introduced in this paper comprises five views on uncertainty (see table 1). In the following we will further describe the views 'sources of uncertainty' (ii), 'factual and normative uncertainty' (iii) and 'causes of uncertainty' (iv). One can say that these are the central views on uncertainty of the concept. The view 'typology of uncertainty on the basis of the theory of probability' (i) is somewhat special as it examines the possibilities and constraints of the theory of probability to describe 
uncertainty in environmental decision-making. The empirical parts of the study have shown that practically this theory isn't used in the implementation of the WFD. The view 'reducibility of uncertainty' (v) already builds a bridge to the basic question about how to deal with uncertainty in environmental decision-making.

\section{Sources of uncertainty}

In the literature the expression 'sources of uncertainty' is often used but rarely explained. Whereas quite a few authors use the term sources to refer to causes we will use this term in the following sense:

Definition of source of uncertainty: Source refers to the reference point of uncertainty. It indicates at what knowledge or what concrete question the uncertainty of a person is related to.

This definition makes it clear that the term 'source' does not have the same meaning as 'cause' (cf. the section about 'causes of uncertainty'). Sources are manifestations of uncertainty in a concrete context. They represent the reference point of the knowledge uncertainty is related to (or the reference point of lacking knowledge). Sources are helpful for a first description and 'localisation' of uncertainty in decision-making. This use of the term source emphasizes the importance of the relational and context specific nature of uncertainty in decision-making.

In the implementation of the WFD for example the competent authorities have to select measures for the programme of measures (Art. 11, 13 WFD). This decision-making process may be structured by the following consecutive seven steps (Klauer et al. 2006):

1. Concretising the goals

2. Pre-selecting measures

3. Assessing the effectiveness of the measures

4. Bundling the measures

5. Selecting a bundle of measures

6. Examining if exemptions can be claimed

7. Constituting and implementing the programme of measures

Every step represents one potential source of uncertainty. As these steps aim to describe the whole selection-process of measures, a description of sources of uncertainty based on this flowchart can claim to be complete. 
But one should be aware that another flowchart may lead to other sources of uncertainty.

\section{Examples for sources of uncertainty in the implementation of the WFD}

In the following example the interviewed expert of the WFD refers to uncertainty in the selection of measures, and more concretely in the assessment of the effectiveness of measures which corresponds with step three in the flowchart above:

Regarding the programme of measures, I think that the most difficult thing will be to identify those measures with the highest degree of effectiveness (expert statement).

The guidance document Impress designates two main sources of uncertainty in the pressures and impacts analysis: Uncertainties relating to the environmental conditions and uncertainties relating to the estimated impacts:

Member States will need to complete the first analyses using appropriate estimates for pressures and impacts but they should be aware, and take account of, the uncertainties in the environmental conditions required to meet the Directives' objectives and the uncertainties in the estimated impacts (Impress 2003).

\section{Factual and normative uncertainty}

Corresponding to the general definition uncertainty is always related to knowledge. The view 'factual and normative uncertainty' distinguishes between uncertainty that is related to factual knowledge and uncertainty that is related to normative knowledge. Both forms of knowledge are very important for decision-making.

In the literature there can be found very different definitions of factual and normative uncertainty (Arentsen et al. 2000; Gottschalk-Mazouz 2003; Newig et al. 2005). Within the scope of the 'concept of uncertainty' developed here we propose the following definitions:

Definition factual uncertainty: Factual uncertainty exists when a person lacks confidence about his/her knowledge regarding facts. 
Definition normative uncertainty: Normative uncertainty exists when a person lacks confidence about his/her knowledge regarding legal or regulatory demands.

Factual knowledge is necessary to describe reality. It asserts one's claims to trueness wherefore it must be verifiable for everybody. Furthermore, it should be impartial. There are many different ways to acquire factual knowledge - from practical experiences to scientific studies.

\section{Examples for factual uncertainty in the implementation of the WFD}

In implementing the WFD the competent authorities need plenty of factual knowledge which often is affected by uncertainty. In the following example the guidance document Wateco calls attention to uncertainty in relation to the programme of measures as the main instrument of the WFD for the achievement of at least 'good status' of all waters:

Uncertainty on costs, effectiveness and time-lagged effects of measures needs to be dealt with throughout the economic analysis process, and more generally throughout the process of identifying measures and developing the river basin management plan (Wateco 2003: 26).

The following statement of an interviewed expert of the WFD refers to the pressures and impacts analysis prescribed by the WFD. Here, the water manager expresses uncertainty relating to hydromorphological pressures and their biological impacts:

When speaking about hydromorphological pressures there are some basic uncertainties concerning the impacts for the biological quality components. For instance, it can't be argued simply that a barrage always affects the acquatic organisms - presumably rather not (expert statement).

Normative uncertainty exists because the European legislator cannot and should not reasonably prescribe every detail of implementation. Every case has to be interpreted and substantiated individually by means of considerations and evaluations. Uncertainty occurring in this context is normative uncertainty. Normative uncertainty can be interpreted in a positive sense, as it gives room for freedom of action and for processes of learning and adaptation - this does not hold for factual uncertainty. However, normative uncertainty also entails the risk of arbitrariness.

The WFD contains many goals and targets that can be interpreted by the Member States in different ways (Kaika 2003: 311). That is also the reason 
why the implementation process of the WFD is regulated by so many guidance documents. But nevertheless, the WFD leaves many questions regarding the implementation to the 'competent authorities' which have to act and decide in the sense of the WFD.

\section{Examples for normative uncertainty in the implementation of the WFD}

Of the analysed guidance documents Impress, Wateco und Proclan, only Impress refers to normative uncertainty. Under the headline 'taking account of uncertainty' it is said (among other things):

The first pressures and impacts analyses must be complete by the end of 2004. However, the environmental conditions required to meet most of the Directive's objectives will not have been firmly defined by this date. For example, the values for the boundaries between the ecological status classes for surface waters are not expected to be finally determined until after the end of the intercalibration exercise (Annex V 1.4 WFD) and the start of the monitoring programmes in 2006 (Article 8) (Impress 2003).

For most of the interviewed water managers normative uncertainty is a big challenge. In the following citation the interviewee refers to the problem that the expression 'good ecological status' used by the WFD has to be interpreted and concretised:

Certainly we will have to define again what we mean exactly by 'good ecological status' or what we want to reach at most because this is also a social political question (expert statement).

In reality it often is difficult to clearly distinguish between factual and normative uncertainty. In the context of decision-making, mostly both forms of knowledge, factual and normative knowledge, are of importance.

Partly, factual and normative uncertainty are interdependent (Morgan and Henrion 1990). If for example in the case of a concrete water body a decision-maker of the WFD has to evaluate if the costs of the selected programme of measures are proportionate or not, he has to know these costs (factual knowledge). If he is uncertain about the costs, also the evaluation of proportionateness is affected by uncertainty. So, normative uncertainty may be rooted in factual uncertainty. On the other hand, factual knowledge to a great extent is determined by normative knowledge. Within the process of pre-selection of measures a decision-maker of the WFD will always prefer those measures which correspond best with his goals and values or rather with his interpretation of the WFD. In general, one can say that fac- 
tual knowledge always is associated with implicit values. Pure factual knowledge or rather pure factual uncertainty does not exist. It depends on the concrete question if a decision-maker concentrates more on factual or more on normative knowledge.

\section{Causes of uncertainty}

When thinking about possible causes of uncertainty we wish to distinguish between 'principal' and 'practical' causes of uncertainty. We begin by considering the principal causes of uncertainty even if the main focus is put on practical causes of uncertainty, illustrated by the example of the WFD.

There are two forms of principal causes of uncertainty: Phenomenological uncertainty and epistemological uncertainty. The first relates to the phenomena, and the second to the state of knowledge of a person. If the question is for example why weather forecasts are affected by uncertainty there are two principal response options: The processes in the atmosphere are not predictable (for instance because of their chaotic behaviour) or our weather models aren't good enough (yet) for a precise description of the relevant processes. In reality, a clear distinction of these two principal causes of uncertainty isn't possible. Uncertainty is rooted always in both, in the phenomena and the observer of these phenomena. This implies that uncertainty is of objective and subjective nature. ${ }^{2}$

Apart from this basic distinction a decision-maker normally tries to identify the practical causes of his uncertainty in a concrete case not at least because this may be helpful to assess the reducibility of uncertainty. The leading question here is: Why isn't it possible to generate 'certain' knowledge?

This question we tried to answer exemplary for the implementation of the WFD. The result is a collection of 'possible causes of uncertainty in the implementation of the WFD' as it is shown in table 2.

\footnotetext{
${ }^{2}$ In the 'Taxonomy of Surprise and Ignorance' of Faber et al. (1992) ,phenomenological ignorance' and ,epistemological ignorance' are two main categories to further describe ,irreducible ignorance'.
} 
Table 2: Possible causes of uncertainty in the implementation of the WFD

1. Uncertainty because of difficulties in describing waterrelated problems.

2. Uncertainty because of difficulties in interpreting and concretising the normative demands of the WFD.

3. Uncertainty because of developments and factors which can't be influenced.

4. Uncertainty because of social interactions and negotiation processes.

5. Uncertainty because of finite financial funds.

In this collection five 'causes of uncertainty' are distinguished. Every item contains a specific issue and partly also represents a specific approach to uncertainty. Hence, there may be some overlapping. Dissimilar to taxonomies the collection is not systematic which as a start can be seen as a disadvantage. However, its advantage is that it is closely linked to practice and that it can be expanded easily. The items one and two correspond to 'factual uncertainty' and 'normative uncertainty'. That is why the following examples of the WFD are restricted to the causes three, four and five.

\section{Examples for causes of uncertainty in the implementation of the} WFD

3. Uncertainty because of developments and factors which can't be influenced:

There are some dependencies which are fairly blatant like agriculture. Agricultural developments we can only influence indirectly mainly via payments, incentive schemes or land purchase (expert statement).

4. Uncertainty because of social interactions and negotiation processes:

There are some difficulties concerning non-point sources.... Here we have a conflict situation affected by relatively strong economic interests.... It is possible that twenty percent of the stakeholders just don't believe in the facts, even if they are proved, that's just the way it is (expert statement).

5. Uncertainty because of finite funds:

In the end we are faced with a financial problem. If I think about the financial situation, the total amount of money necessary to implement the WFD then I am really concerned (expert statement). 


\section{Concluding remarks}

The question "How to deal appropriately with uncertainty" should be addressed in two stages: (i) Grasping and describing uncertainty and (ii) deciding and acting under uncertainty. In this paper we were mainly concerned about the first stage.

Our concept for describing uncertainty enables a decision maker to assess the trustworthiness and reliability of the knowledge base of his actions and decisions. It guides him in getting, on the one hand, an overview and, on the other hand, a deeper understanding of the different facets of uncertainty in environmental decision making. The following prototypic proceeding for describing uncertainty in the context of the WFD is recommended:

1. Detection of potential sources of uncertainty and, if applicable, prioritisation of these sources.

2. Characterisation of these sources with respect to the categories factual and normative uncertainty.

3. Detection of relevant causes of uncertainty by the help of the collection of causes.

4. Assessment of the reducibility of uncertainty.

This proceeding enables the decision maker to get a differentiated and systematic description of the uncertainty and provides a knowledge base that at the same time gives information about what is known, what is not known, and what can be expected or assumed. In doing so, his knowledge base will be enlarged by information about his confidence in his knowledge.

The analysis of the interviews with WFD-experts and of the guidance documents reveals that all facets of uncertainty addressed by our concept, indeed, play a role in the praxis of implementing the WFD. However, uncertainty is not systematically analysed neither in the guidance documents nor in the daily work of the interviewed experts. Their approach towards describing as well as dealing with uncertainty can be characterised as a "muddling through": The experts act on the basis of their practical experience in dealing with similar situations and more or less ad-hoc solutions are put forward.

In contrast to this, the scientific approaches typically describe the uncertainty of a decision in a systematic manner. Their standard approach is the quantification of uncertainty by probabilities. However, they are not able to grasp all different facets of uncertainty and they are rather demanding with respect to data and information needed for determining probabilities. 
For example, the decision maker needs to know all potential outcomes of an uncertainty situation. Therefore, our opinion is that the dominating scientific approaches to uncertainty rooted in decision theory are in many situations not appropriate for supporting good decision making - at least without supplementation.

Our concept for describing uncertainty tries to bridge the gap between the "muddling through" of the practitioners and the demanding, but narrow analytical approach of the scientists. It emphasizes the context dependent nature of uncertainty which corresponds to a more realistic description of real world decision situations.

\section{Acknowledgements}

This article is based on work carried out within the Project 'Harmonised Techniques and Representative River Basin Data for Assessment and Use of Uncertainty Information in Integrated Water Management (HarmoniRib)', which is partly funded by the EC Energy, Environment and Sustainable Development programme (Contract EVK1-CT-2002-00109).

\section{References}

Arentsen, M.J., Bressers, H.T.A. \& O'Toole, L.J. (2000): Institutional and policy responses to uncertainty in environmental policy: A comparison of Dutch and US styles. Policy Studies Journal 28(3), S. 597-611.

BMU (2007): Time To Adapt. Climate Change and the European Water Dimension. Vulnerability - Impacts - Adaptation. Conclusions from the International Symposium, 12.-14. Februar 2007 Berlin.

Brown, J.D., Heuvelink, G.B.M. \& Refsgaard, J.C. (2005): An integrated framework for assessing and recording uncertainties about environmental data. Water Science and Technology 52(6), S. 153-160.

Faber, M. \& Manstetten, R. (2003): Mensch - Natur - Wissen. Grundlagen der Umweltbildung. Vandenhoeck \& Ruprecht, Göttingen.

Faber, M., Manstetten, R. \& Proops, J.L.R. (1992): Humankind and the Environment: An Anatomy of Surprise and Ignorance. Environmental values 1, S. 217-242.

Funtowicz, S.O. \& Ravetz, J.R. (1990): Uncertainty and Quality in Science for Policy. Springer, Berlin.

Gottschalk-Mazouz, N. (2003): Wissen, Ungewissheit und Abduktion: Fundierung eines allgemeinen Modells zur Analyse von Dissensen in der Wissenschaft. In: Gottschalk-Mazouz, N. \& Mazouz, N. (eds.), Nachhaltigkeit und globaler 
Wandel. Integrative Forschung zwischen Normativität und Unsicherheit, S. 23-60. Campus Verlag, Frankfurt.

Handmer, J.W., Norton, T.W. \& Dovers, S.R. (eds.) (2001): Ecology, Uncertainty and Policy. Managing Ecosystems for Sustainability. Pearson Education Limited, Harlow.

Harremoes, P. (2003): The Need to Account for Uncertainty in Public Decision Making Related to Technological Change. Integrated Assessment 4(1), S. 1825.

Impress (2003): Analysis of Pressures and Impacts. Common Implementation Strategy for the Water Framework Directive, Guidance Document Nr. 3.

Kaika, M. (2003): The Water Framework Directive: A New Directive for a Changing Social, Political and Economic European Framework. European Planning Studies 11(3), S. 299-316.

Klauer, B. \& Brown, J.D. (2004): Conceptualising imperfect knowledge in public decision making: ignorance, uncertainty, error and 'risk situations'. Environmental Research, Engineering and Management 27(1), S. 124-128.

Klauer, B., Petry, D. \& Rode, M. (2006): Flussgebietsmanagement nach EUWasserrahmenrichtlinie - Entscheidungsunterstützung für die Aufstellung von Maßnahmenprogrammen illustriert am Beispiel der Weißen Elster.

Klauer, B., Rode, M. \& Petry, D. (eds.) (in press): Flussgebietsmanagement nach EG-Wasserrahmenrichtlinie. Metropolis, Marburg.

Morgan, M.G. \& Henrion, M. (1990): Uncertainty. A Guide to Dealing with Uncertainty in Quantitative Risk and Policy Analysis. Cambridge University Press, Cambridge.

Newig, J., Pahl-Wostl, C. \& Sigel, K. (2005): The Role of Public Participation in Managing Uncertainty in the Implementation of the Water Framework Directive. European Environment. The Journal of European Environmental Policy 15(6), S. 333-343.

Pahl-Wostl, C. (2002): Towards sustainability in the water sector - The importance of human actors and processes of social learning. Aquatic Sciences 64, S. 394-411.

Pahl-Wostl, C. (2007): The implications of complexity for integrated resources management. Environmental Modelling and Software 22, S. 561-569.

Pahl-Wostl, C., Isendahl, N., Möllenkamp, S., Brugnach, M., Jeffrey, P., Medema, W. \& de Vries, T.T. (2006): Paradigms in Water Management. Report of the NeWater project - New Approaches to Adaptive Water Management under Uncertainty.

Proclan (2003): Planning process. Common Implementation Strategy for the Water Framework Directive, Guidance Document Nr. 11.

Sigel, K. (in press): Umweltprobleme und Unsicherheit. Eine konzeptionelle und empirische Analyse am Beispiel der EG-Wasserrahmenrichtlinie. Metropolis, Marburg (in press).

Smithson, M. (1989): Ignorance and Uncertainty: Emerging Paradigms. Springer, New York.

van Asselt, M.B.A. (2000): Perspectives on Uncertainty and Risk. The PRIMA Approach to Decision Support. Kluwer Academic Publishers, Dordrecht. 
Walker, W.E., Harremoes, P., Rotmans, J., Sluijs, J.P.v.d., van Asselt, M.B.A., Janssen, P. \& von Krauss, K.M.P. (2003): Defining Uncertainty. A Conceptual Basis for Uncertainty Management in Model-Based Decision Support. Integrated Assessment 4(1), S. 5-17.

Walker, W.E. \& Marchau, V.A.W.J. (2003): Dealing With Uncertainty in Policy Analysis and Policymaking. Integrated Assessment 4(1), S. 1-4.

Wateco (2003): Economics and the Environment - The Implementation Challenge of the Water Framework Directive. Common Implementation Strategy for the Water Framework Directive, Guidance Document No. 1.

Wynne, B. (1992): Uncertainty and environmental learning. Reconceiving science and policy in the preventive paradigm. Global Environmental Change 2, S. 111-127. 